\title{
$\nabla$
}

\section{Impact of chronic urticaria on the quality of life of patients followed up at a university hospital *}

\author{
Gabriela Andrade Coelho Dias ${ }^{1}$ \\ Solange Oliveira Rodrigues do Valle ${ }^{2}$ \\ Soloni Levy ${ }^{3}$ \\ Ilaria Baiardini ${ }^{4}$
}

\author{
Gisele Viana Pires ${ }^{2}$ \\ Sérgio Duarte Dortas Júnior ${ }^{2}$ \\ Alfeu Tavares França² \\ Walter Giorgio Canonica ${ }^{4}$
}

DOI: http://dx.doi.org/10.1590/abd1806-4841.20165071

\begin{abstract}
BACKGROUND: Chronic urticaria is a debilitating disease that considerably affects health-related quality of life, and the Chronic Urticaria Quality of Life Questionnaire is the only questionnaire specifically designed for its evaluation.

Овлестіvе: To evaluate the quality of life of patients with chronic urticaria, using the Brazilian Portuguese version of the Chronic Urticaria Quality of Life Questionnaire.

Methods: The Chronic Urticaria Quality of Life Questionnaire was self-administered in 112 chronic urticaria patients and disease activity was assessed through the Urticaria Activity Score. Clinical and socio-demographic characteristics of patients were studied, such as: age, sex, etiologic diagnosis of chronic urticaria, duration of disease and Urticaria Activity Score.

RESULTS: The population studied was composed $85.72 \%$ of women with a mean age of 46 years (18-90), while the median disease duration period was 10 years (3 months-60 years). Regarding the etiologic diagnosis, $48.22 \%$ had chronic spontaneous urticaria; $22.32 \%$ associated with inducible urticaria, $28.57 \%$ with chronic autoimmune urticaria, and $23.21 \%$ had physical urticaria alone. Disease activity evaluated using the Urticaria Activity Score was $1.04 \pm 1.61$ (0-6). The total score for the Chronic Urticaria Quality of Life Questionnaire was 36 (0-100) and dimension I (sleep/mental status/eating) had a greater impact on quality of life. The items with the highest mean scores were nervousness and shame over lesions, while the items with the lowest scores were lip swelling and limitations on sporting activities.

CONCLUSIONS: Chronic urticaria compromises patients' quality of life, mainly those with more severe disease or who are diagnosed with chronic autoimmune urticaria.
\end{abstract}

Keywords: Angioedema; Quality of Life; Questionnaires; Urticaria

\section{INTRODUCTION}

Chronic urticaria (CU) is a debilitating allergic skin disease, which affects 0.5 to $1 \%$ of the population and is characterized by erythematous, papulous and ichty lesions of a fluctuating nature that persist for over six weeks. ${ }^{1}$ It is highly complex in relation to its etiology and treatment is challenging, even for experts.

Quality of life (QoL) has become an important subject for society and especially for health professionals. It can be defined as the individual satisfaction or happiness with life in domains that the subject considers important. Several factors may affect a subject's well-being, such as work, housing and financial concerns. Health is but one of these factors. The expression "health-related quality of life" (HRQoL) was thus developed to refer to the disease's impact on and therapy in a patient's life, according to his/her perception.
Hence, it is a subjective evaluation from the patient regarding the impact of health status on his/her full ability of living. ${ }^{2}$

In recent decades, the incorporation of patients' perceptions into decision-making over the handling of diseases has been an essential factor in improving the QoL of health assistance models. The incapacity of traditional clinical parameters to express what people feel and think has led to increased interest in the HRQoL field from the scientific community. ${ }^{3}$

$\mathrm{CU}$ interferes with subjective well-being and daily life; some patients` health status is comparable to that of coronary artery disease and severe asthma patients. It also causes inconvenience in family structures, compromising performance at work, school, and negatively impacting on leisure activities. ${ }^{4,5}$

Approved by the Advisory Board and accepted for publication on 16.01.2016

* Work performed at the Hospital Universitário Clementino Fraga Filho - Universidade Federal do Rio de Janeiro (HUCFF-UFRJ) - Rio de Janeiro (RJ), Brazil. Financial support: None.

Conflict of interest: None.

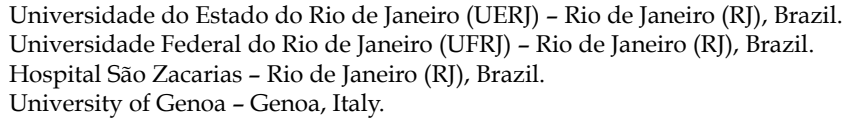


Skin pruritus causes variable discomfort, as well as lesions, which, depending on their number and location, may harm an individual's physical appearance and social life. ${ }^{6}$

Sleep disorders such as insomnia, fatigue and drowsiness due to pruritus or side effects from antihistamines - are frequently observed. Patients complain of recurrent pain syndromes, including tension headaches and fibromyalgia, while the prevalence of psychiatric disorders, like depression, hysteria, hypochondria and post-traumatic stress disorder is high..$^{7-9}$

The degree to which quality of life is affected varies according to the chronic urticaria's etiology and severity. When CU is associated with delayed pressure urticaria, it affects quality of life more significantly than urticaria alone. ${ }^{4}$

HRQoL evaluation of patients with $\mathrm{CU}$ is essential for a better assessment of disease progression and treatment response. In 2005, Baiardini et al. developed and validated a specific questionnaire to evaluate the HRQoL in CU: the Chronic Urticaria Quality of Life Questionnaire (CU- $\left.\mathrm{Q}_{2} \mathrm{OL}\right)$, which has been shown to, have satisfactory psychometric properties. ${ }^{10}$ The $\mathrm{CU}-\mathrm{Q}_{2} \mathrm{OL}$, originally written in Italian, was already successfully validated in Spanish, German, Polish, Turkish, Brazilian Portuguese, Korean, Greek and Persian. ${ }^{11-18}$

This study sought to evaluate the HRQoL in CU patients followed up at the outpatient chronic urticaria clinic of Hospital Universitário Clementino Fraga Filho (HUCFF) - Universidade Federal do Rio de Janeiro (UFRJ), who have participated in the transcultural validation process of the Brazilian Portuguese version of the CU- $\mathrm{Q}_{2} \mathrm{OL}$, recently adapted and validated by our group ${ }^{15}$.

\section{METHODS}

This was a cross-sectional study conducted in the same patient's sample evaluated in the Brazilian Portuguese cross-cultural adaptation of the CU- $Q_{2} \mathrm{oL}$ study, published in $2011^{15}$. The study population comprised both male and female patients aged over 18, clinically diagnosed with chronic urticaria, characterized by the ocurrence of erythematous, papulous, pruriginous lesions, for a period of over six weeks, screened from July 2009 to August 2010 at the HUCFF urticaria outpatient clinic. The study excluded patients diagnosed with acute urticaria, contact urticaria, urticarial vasculitis, angioedema with no urticaria, patients unable to understand study terms and to give written consent, and patients with associated psychiatric comorbidities - 156 patients were evaluated and 44 were excluded. The study was approved by the Hospital Ethics Committee, and all patients provided written informed consent to participate.

The Brazilian version of CU- $\mathrm{Q}_{2} \mathrm{OL}$ includes 23 items that are divided into three dimensions: sleep/mental status/eating, pruritus/impact in daily activities, and limitations/appearance/edema. ${ }^{19}$

The questionnaire refers to the preceding two weeks, and the patients indicate the intensity of each item separately, on a 5-point Likert scale, ranging from $1=$ "not at all" to $5=$ "very much". A score is calculated for each dimension, then a total index is calculated for all the dimensions. The score ranges from 0 to 100 . The higher the score, the worse the patient's perception of his/her quality of life is.
Urticaria severity was evaluated using the score proposed by Zurberbier et al. (2001); and disease severity was assessed via the UAS - Urticaria Activity Score. The score evaluates the number of lesions and pruritus intensity. The sum of scores obtained by evaluating urticaria and pruritus ranges from 0 to 6 , where 0 corresponds to controlled disease, while 6 corresponds to high intensity disease. ${ }^{20}$

The following clinical and socio-demographic characteristics of the patients were studied, such as: age (18-40 years, 4160 years, $>60$ years), sex, etiologic diagnosis of chronic urticaria (chronic spontaneous urticaria, chronic autoimmune urticaria and inducible urticaria), time to disease progression ( $<$ and $>5$ years) and UAS (group 1: scores 0 and 1; group 2: scores 2, 3 and 4; group 3 : scores 5 and 6). Moreover, the ANOVA analysis was used to evaluate the differences between the groups.

Statistical analysis was performed through SPSS 17.0 and Stata 8.0. A descriptive statistical analysis was used in the clinical and demographic characterization of the patients studied, and an analysis of variance (ANOVA) was applied to compare three or four independent means - $\mathrm{p}<0.05$ was considered statistically significant.

This study and the respective informed consent form were approved by the Hospital Ethics Committee.

\section{RESULTS}

The population studied consisted of 96 female patients $(85.72 \%)$ and 16 male patients $(14,28 \%)$, with a mean age of 46 years (18-90) and a mean family income of $\mathrm{R} \$ 1,828.66$. In this sample, $58.03 \%$ of patients were married, $37.5 \%$ had not completed elementary school, and $8.03 \%$ had completed higher education, $49.11 \%$ were employed, $27.68 \%$ were homemakers, and $13.40 \%$ were retired (Table 1).

The mean time to disease progression was 10 years (3 months - 60 years), and the follow-up time at hospital was 4 years. Regarding the etiologic diagnosis, $48.21 \%$ of patients had chronic spontaneous urticaria (CSU), $22.32 \%$ associated with physical urticaria, $28.57 \%$ had chronic autoimmune urticaria (CAU) and $23.21 \%$ had inducible urticaria alone. Furthermore, $59.82 \%$ of patients required continuous treatment with antihistamines (Table 2).

Disease activity evaluated by UAS score was $1.04 \pm 1.61(0-$ 6). Of the 112 patients enrolled in the study, 8 (7\%) did not answer at least one question from the CU- $\mathrm{Q}_{2} \mathrm{OL}$. The item with the highest ratio of blank answers was item 4 (lip swelling). The mean total score for the questionnaire was 36 , while dimension I had the highest score; however, the score values were homogeneous for all three dimensions (Table 3).

The items with the highest mean scores were 15 (nervousness), followed by 18 (shame over lesions) and 1 (pruritus). The lowest scores were item 4 (lip swelling) and 22 (limtations on sporting activity) (Table 4).

Seventy-five percent of the patients were not doing sporting activities and only $16 \%$ indicated chronic urticaria as the reason for this. Of the 28 patients who played sports, $42.8 \%$ mentioned that urticaria interfered a little, somewhat, or too much in sporting activity-related quality of life. Of the 13 patients who were not practicing sports due to urticaria, $69 \%$ reported that urticaria affected much or very much.

ANOVA analysis showed that patients aged $41-60$ years were 
patients with autoimmune urticaria were more impacted in dimension III, compared with patients suffering from chronic spontaneous urticaria and inducible urticaria alone. Women were more affected in all dimensions but not in a statistically significant manner. Patients with higher severity scores (group 3 ) experienced a greater impact on quality of life in the total score, and in dimensions II and III (Table 5).

TABLE 1: Socio-demographic characteristics

\begin{tabular}{ll}
\hline Variable & $\mathrm{n}=112$ \\
\hline Sex (n/\%) & $16(14.28)$ \\
$\quad$ Male & $96(85.72)$ \\
Female & 46 years old (18-90) \\
Age (variation) & \\
Marital status (n/\%) & $65(58.03)$ \\
$\quad$ Married & $29(25.90)$ \\
Single & $7(6.25)$ \\
Divorced & $11(9.82)$ \\
Widow/widower & \\
Scholarship (n/\%) & $42(37.50)$ \\
Uncompleted elementary school & $19(16.97)$ \\
$\quad$ Elementary school & $37(33.04)$ \\
High school & $9(8.03)$ \\
Higher education & $5(4.46)$ \\
Post-graduate & \\
Occupation (n/\%) & $55(49.11)$ \\
Employee & $31(27.68)$ \\
Homemaker & $15(13.40)$ \\
Retired & $5(4.46)$ \\
Student & $6(5.35)$ \\
Unemployed & $\mathrm{R} \$ 1,828.66-\mathrm{R} \$ 2,015.86$ \\
Income (standard deviation-SD) & \\
\hline
\end{tabular}

TABLE 2: Sample clinical characteristics

\begin{tabular}{|c|c|}
\hline Variable & $\mathrm{n}=112$ \\
\hline $\begin{array}{l}\text { Time to disease progression } \\
\text { (variation/SD) }\end{array}$ & $\begin{array}{l}10.6 \text { years ( } 3 \text { months to } 60 \\
\text { years } / 10.6 \text { years) }\end{array}$ \\
\hline $\begin{array}{l}\text { Time of follow-up on the job } \\
\text { (variation/SD) }\end{array}$ & 4 years ( 0 to 25 years $/ 4.4$ years) \\
\hline Type of urticaria (n/\%) & \\
\hline Chronic spontaneous urticaria & \\
\hline Alone & $29(25.90)$ \\
\hline $\begin{array}{l}\text { Associated with inducible } \\
\text { urticaria }\end{array}$ & $25(22.32)$ \\
\hline Autoimmune urticaria & \\
\hline Alone & $8(7.15)$ \\
\hline $\begin{array}{l}\text { Associated with inducible } \\
\text { urticaria }\end{array}$ & $24(21.42)$ \\
\hline Inducible urticaria alone & $26(23.21)$ \\
\hline Continuous use of drugs (n/\%) & $67(59.82)$ \\
\hline
\end{tabular}

\section{DISCUSSION}

CU seriously compromises the HRQoL of patients due to debilitating and uncomfortable symptoms that may last for years. ${ }^{5}$

In addition to classic symptoms, like pruritus and papules, other factors are more relevant for patients with chronic urticaria, such as unpredictability of flares, sleep disorders, fatigue, drug-related side effects, and physical appearance. Thus, merely evaluating urticaria progress by counting lesions and measuring pruritus intensity is insufficient. A holistic evaluation of the patient is required for a better understanding of disease impact. In 2010, the Global Allergy and Asthma European Network $\left(\mathrm{GA}_{2} \mathrm{LEN}\right)$ study group recommended evaluating the Patient-Reported Outcomes (PRO) and HRQoL in clinical trials on allergy, recognizing the importance of better knowledge of subjective evaluation of patients in relation to health status factors. ${ }^{21}$

Most studies on quality of life concerning chronic urticaria have used generic questionnaires or those for dermatological diseases, such as the DLQI (Dermatology Life Quality Index), which was validated as a useful instrument to evaluate the HRQoL of patients with chronic urticaria. ${ }^{22}$ However, the DLQI can be used for any dermatological disease, since it was not developed specifically chronic urticaria patients and may not measure important factors concerning them. CU- $\mathrm{Q}_{2} \mathrm{OL}$ is a valid and specific instrument to

TABLE 4: Item scores

\begin{tabular}{llc}
\hline Item & Mean Score (0-100) \\
\hline 1 & Pruritus & 49.0 \\
2 & Wheals & 37.5 \\
3 & Eyes swelling & 20.8 \\
4 & Lip swelling & 12.6 \\
5 & Work & 40.5 \\
6 & Physical activities & 25.1 \\
7 & Sleep & 41.5 \\
8 & Free time & 29.5 \\
9 & Social relationships & 31.2 \\
10 & Eating & 28.2 \\
11 & Falling asleep & 36 \\
12 & Waking up at night & 44.3 \\
13 & Tired & 43.3 \\
14 & Concentration & 37.5 \\
15 & Nervousness & 55.0 \\
16 & Bad Mood & 39.3 \\
17 & Limits foods & 35 \\
18 & Embarrassed by signs & 52.8 \\
19 & Embarrassed in public & 36.8 \\
20 & Cosmetics & 39.5 \\
21 & Limits clothes & 37.8 \\
22 & Sports & 17.5 \\
23 & Medication side effects & 41.8 \\
\hline
\end{tabular}

TABLE 3: CU-Q2oL dimension scores

\begin{tabular}{llll}
\hline Dimension & Item (0-100) & Mean score & SD \\
\hline Total score & & 36 & 22 \\
I - Sleep/mental status/eating & $10,11,12,13,14,15,16,17$ & 39.9 & 24.7 \\
II - Pruritus/impact on daily activities & $1,2,5,6,7,8,9,22$ & 34.4 & 26.4 \\
III - Edema/limitations/appearance & $3,4,18,19,20,21,23$ & 34.8 & 24.8 \\
\hline
\end{tabular}


TABLE 5: Distribution of scores and clinical characteristics

\begin{tabular}{|c|c|c|c|c|}
\hline & Total score $0-100 / n$ & $\begin{array}{l}\text { Sleep / mental status / } \\
\text { eating (0-100) }\end{array}$ & $\begin{array}{l}\text { Pruritus / impact on } \\
\text { daily activities (0-100) }\end{array}$ & $\begin{array}{l}\text { Edema / limitations / } \\
\text { appearance (0-100) }\end{array}$ \\
\hline \multicolumn{5}{|l|}{ Sex } \\
\hline Female & $36.30(96)$ & 40.42 & 41.63 & 35.84 \\
\hline Male & $36.06(16)$ & 36.94 & 33.30 & 28.88 \\
\hline \multicolumn{5}{|l|}{ Age } \\
\hline $18-40 y$ & $33.03(36)$ & $32.50^{\mathrm{a}}$ & 35.58 & 31.53 \\
\hline $41-60 y$ & $41.07(56)$ & $48.32^{\mathrm{a}}$ & 37.64 & 37.50 \\
\hline$>60 y$ & $28.65(20)$ & $29.75^{\mathrm{a}}$ & 23.70 & 33.40 \\
\hline \multicolumn{5}{|l|}{ Type } \\
\hline Spontaneous & $38.53(54)$ & 40.53 & 38.79 & $36.66^{\mathrm{b}}$ \\
\hline Autoimmune & $40.47(32)$ & 46.16 & 34.81 & $41.28^{\mathrm{b}}$ \\
\hline Inducible alone & $27.50(26)$ & 31.69 & 26.65 & $24.31^{\mathrm{b}}$ \\
\hline \multicolumn{5}{|l|}{ Disease duration } \\
\hline$<5$ years & $35.66(47)$ & 39.09 & 36.04 & 31.66 \\
\hline$>5$ years & $36.71(65)$ & 40.52 & 33.06 & 37.15 \\
\hline \multicolumn{5}{|l|}{ Groups UAS } \\
\hline 1 & $32.06^{\mathrm{a}}(85)$ & 37.34 & $28.06^{c}$ & $31.29^{\mathrm{d}}$ \\
\hline 2 & $46.53^{\mathrm{a}}(19)$ & 48.16 & $47.47^{c}$ & $44.37^{\mathrm{d}}$ \\
\hline 3 & $56.63^{\mathrm{a}}(8)$ & 47.75 & $72.00^{c}$ & $50.00^{\mathrm{d}}$ \\
\hline
\end{tabular}

a: $p=0,001, b: p=0,03, c: p<0,0001, d: p=0,02$

concerning them. CU- $\mathrm{Q}_{2} \mathrm{OL}$ is a valid and specific instrument to evaluate the HRQoL. It is easily applied and requires five minutes to be completed by the patient. ${ }^{10}$ This study aimed to evaluate the impact of chronic urticaria on the quality of life of patients followed up at a university outclinic, to determine which aspects of quality of life affected these patients the most.

The population evaluated in this study showed a high prevalence of chronic urticaria in women (85.72\%). Epidemiological studies demonstrate that occurrence is twice as high in female patients. ${ }^{23}$ A population investigation conducted in Germany demonstrated that in a sample of 4,093 people, $1.8 \%$ had CU, of which $70.3 \%$ were women, while the sample from the CU- $\mathrm{Q}_{2} \mathrm{OL}$ original study included $61.84 \% .{ }^{10,24}$ It is frequently noted that women are more affected by chronic urticaria and other autoimmune diseases.

In most studies, the peak age of CU occurrence is between 20 and 40 years. ${ }^{25}$ Thus, patients are mainly affected during their working life years and are more prone to absenteeism and decreased productivity because of illness and its treatment. A Spanish study observed that the mean age of patients was $35.75 \pm 18.9$ years and this study population had a mean age of 46 years (18-70 years). ${ }^{26}$

Patients had a high educational level compared with the overall population, with $45 \%$ having at least completed high school, similarly to the findings of the original study $(51.31 \%) .{ }^{10}$ The average income was $\mathrm{R} \$ 1,828.66$, while the average income of Brazilian families in 2010 was $\mathrm{R} \$ 1,292.00 .{ }^{27}$ Many diseases have a prevalence standard, which is dependent on socio-economic and educational levels. With respect to urticaria, there is little data available on this issue. Several studies were not able to show a difference in the prevalence of urticaria in terms of educational level, occupation, income, residence location, and ethnic origin..$^{24,26}$

The mean time to disease progression was 10.6 years ( 3 months-60 years). In the Baiardini et al. study, the time was shorter, around 1 year and 9 months (SD: 27.32 months)..$^{10}$ Gaig et al. found that $50 \%$ of $\mathrm{CU}$ patients were asymptomatic in three months, and $80 \%$ in 12 months. However, $11 \%$ were affected for over five years. ${ }^{28}$ In most cases, chronic urticaria typically remits after 1-5 years, though $10-20 \%$ of cases may last 5-10 years and some can persist for up to 50 years. Patients with severe urticaria at diagnosis usually experience longer durations. In our population, $61 \%$ of patients presented the disease for over five years. The authors believe that the high frequency of long-lasting cases in these series is due to the institution being a reference center, which tends to recruit severe and refractory cases.

Regarding the etiology of chronic urticaria, just like in the medical literature, a higher prevalence of CSU (48.21\%) was observed, followed by CAU (28.56\%), and physical urticaria alone (23.21\%). ${ }^{1}$ Nevertheless, when all patients with inducible urticaria (alone and associated) were considered, a prevalence of $66.95 \%$ was found. In the Spanish study, patients experienced chronic spontaneous urticaria in $68 \%$ of cases, and physical urticaria in $60 \% .^{11}$ About half of the study population did not have an etiologic diagnosis despite having undergone a complete research protocol with challenge tests for physical urticaria and an autologous serum test. Affected patients with chronic spontaneous urticaria suffer deep frustration because of the uncertainty about the cause of their disease, which reduces their quality of life.

The first application of the Brazilian Portuguese version of $C U-Q 2 o L$ showed that it is a useful tool to evaluate the disease more specifically.

The dimension score was not elevated, ranging from 34.4 to 39.9 on a scale of 0 to 100 . This is because the study population was very heterogeneous, encompassing patients with different types of urticaria at various stages of disease progression. The mean UAS score was low $(1.04 \pm 1.61$ [0-6]), as 66 patients (58\%) were asymptomatic on evaluation day.

Dimension I (sleep/mental state/eating) revealed a greater 
the disease entails sleep disorders, causing significant damage to mental health, as well as chronic fatigue, loss of professional productivity and commitment to their personal and social lives. Previous studies have reported that chronic urticaria has a significant impact on quality of life, especially as regards sleep and energy, which is consistent with our results. ${ }^{4,29,30}$

Question 15, "nervousness", had the highest score (55). This finding confirms the high impact of chronic urticaria on the patients' mental health. Pasaoglu et al. demonstrated that patients with chronic spontaneous urticaria had a higher prevalence of depression, hysteria, hypochondria, and conflicts with their social environment. $^{8}$

The questions "embarrassed by signs" and "pruritus" also revealed a great impact on quality of life, as the first question assesses patients feelings and the second, the main and most troublesome symptom of this disease, which interferes with daily activities and mental health.

The question on "lip swelling" had the lowest score, like in the Spanish study. ${ }^{11}$ Sporting activities were not regarded as relevant by the patients either, probably because $75 \%$ of the patients involved in this study were not practicing sports and urticaria was the reason for only $13 \%$ of them. The precursor O’Donnel study showed that $45 \%$ of $\mathrm{CU}$ patients reported limitations for running. ${ }^{4}$

Regarding gender, women were expected to be more affected than men. ${ }^{12,31}$ Women likely have more sensitive skin and mental awareness toward the symptoms of hives and are more influenced by changes in appearance. In fact, a greater impact was found in all dimensions for women, though there was no statistical significance.

In relation to age, patients aged between 41 and 60 years had a higher impact in dimension I. This age group includes adults at the peak of their professional lives, and disturbances in sleep and mental state limit their working lives.

Variance analysis of $\mathrm{CU}-\mathrm{Q}_{2} \mathrm{oL}$ results showed that patients with autoimmune urticaria (CAU) had the worst quality of life in dimension III (edema, appearance, and limitations). Several studies evaluating disease severity have concluded that patients with positive autologous serum skin tests were more affected than those with negative tests. ${ }^{23}$ A multicenter study published in 2009 revealed the highest disease severity and worst quality of life measured by DLQI in patients with positive autologous serum skin tests. ${ }^{32}$

Severity assessment (UAS) demonstrated a strong correlation with the quality of life impact. Patients with more severe disease showed greater degree of impairment, especially in dimension II (itching/impact on daily activities).

In Brazil, there are few studies evaluating HRQoL in patients with chronic urticaria. However, it was shown that these patients underwent an important change in QoL; the most affected domains were food restrictions, emotional changes and quality of sleep. ${ }^{33}$ A study published in 2011 using DLQI and SF-36, a generic instrument to evaluate quality of life, demonstrated greater impairment in: women, patients aged up to 30 , those experiencing their first visit, patients with a high level of education, those who had the disease for up to 1 year, and angioedema patients. ${ }^{31}$ In another Brazilian study published in 2011, the patients had a mean score of 13.5 in the DLQI (0-30), the presence of angioedema was associated with higher scores $(14.3 ; \mathrm{p}<0.01)$; women were more limited with respect to clothing and men with respect to work and study $(p<0.05) \cdot{ }^{34}$ In these studies, the presence of angioedema and being female were associated with a worse quality of life. This study highlights a tendency toward a worse quality of life in women. The difference between patients with and without angioedema was not assessed. There is a need for further studies to define the predictive factors that affect quality of life in the Brazilian population.

\section{CONCLUSION}

Chronic urticaria seriously compromises the quality of life of patients due to its debilitating symptoms that can last for years. In this study, a major impairment was observed in patients with the highest severity and in those diagnosed with autoimmune urticaria. An evaluation of quality of life is fundamental to better assess disease progression and treatment efficacy, as per recommended by the $\mathrm{GA}_{2} \mathrm{LEN}$. In the future, the Brazilian Portuguese version of the $\mathrm{CU}-\mathrm{Q}_{2} \mathrm{OL}$ may enable multicenter studies to be performed, in addition to promoting an overall understanding of the impact of chronic urticaria.] 


\section{REFERENCES}

1. Zuberbier T1, Asero R, Bindslev-Jensen C, Walter Canonica G, Church MK, Giménez-Arnau AM, et al. EAACI/GA(2)LEN/EDF/WAO guideline: management of urticaria. Allergy. 2009;64:1427-43.

2. Gerin P, Dazord A, Boissel J, Chifflet R. Quality of life assessment in therapeutic trials: rationale for and presentation of a more appropriate instrument. Fundam Clin Pharmacol. 1992;6:263-76.

3. Minayo M, Hartz Z, Buss P. Qualidade de vida e saúde: um debate necessário. Ciênc. Saúde Colet. 2000;5:7-18.

4. O'Donnell BF, Lawlor F, Simpson J, Morgan M, Greaves MW. The impact of chronic urticaria on the quality of life. Br J Dermatol. 1997;136:197-201.

5. Baiardini I, Giardini A, Pasquali M, Dignetti P, Guerra L, Specchia C, et al. Quality of life and patients' satisfaction in chronic urticaria and respiratory allergy. Allergy. 2003;58:621-3.

6. Yosipovitch G, Ansari N, Goon A, Chan YH, Goh CL. Clinical characteristics of pruritus in chronic idiopathic urticaria. Br J Dermatol. 2002;147:32-6.

7. Weldon DR. Quality of life in patients with urticaria. Allergy Asthma Proc. 2006:27:96-9.

8. Pasaoglu G. Psychological status of patients with chronic urticaria. J Dermatol. 2006:33:765-71.

9. Chung MC, Symons C, Gilliam J, Kaminski ER. The relationship between posttraumatic stress disorder, psychiatric comorbidity, and personality traits among patients with chronic idiopathic urticaria. Compr Psychiatry. 2010;51:5563.

10. Baiardini I1, Pasquali M, Braido F, Fumagalli F, Guerra L, Compalati E, et al. A new tool to evaluate the impact of chronic urticaria on quality: chronic urticaria quality of life questionnaire (CU-Q2oL). Allergy. 2005;60:1073-8.

11. Valero A, Herdman M, Bartra J, Ferrer M, Jáuregui I, Dávila I, et al. Adaptation and validation of the Spanish version of the Chronic Urticaria Quality of Life Questionnarie (CU-Q20L). J Investig Allergol Clin Immunol. 2008;18:426-32.

12. Młynek A, Magerl M, Hanna M, Lhachimi S, Baiardini I, Canonica GW, et al. The German version of the Chronic Urticaria Quality-of-Life Questionnaire: factor analysis, validation, and initial clinical findings. Allergy. 2009;64:927-36

13. Brzoza Z, Badura-Brzoza K, Młynek A, Magerl M, Baiardini I, Canonica GW, et al. Adaptation and initial results of the Polish version of the GA2LEN Chronic Urticaria Quality Of Life Questionnaire (CU-Q2oL). J Dermatol Sci. 2011;62:36-41.

14. Kocatürk E, Weller K, Martus P, Aktas S, Kavala M, Sarigul S, et al. Turkish Version of the Chronic Urticaria Quality of Life Questionnaire: Cultural Adaptation, Assessment of Reliability and Validity. Acta Derm Venereol. 2012;92:419-25.

15. Dias GA, Pires GV, Valle SO, França AT, Papi JA, Dortas SD Jr, et al. Cross-cultural adaptation of the Brazilian-Portuguese version of the chronic urticaria quality-oflife questionnaire - CU-Q20L. Allergy. 2011;66:1487-93.

16. Lee EH, Park JW, Kim C, Kim SH, Lee Y, Choi JH, et al. Development and psychometric evaluation of chronic urticaria-specific quality of life scale (CUQOL). Korean J Asthma Allergy Clin Immunol 2010;30:S384.

17. Koti I1, Weller K, Makris M, Tiligada E, Psaltopoulou T, Papageorgiou C, et al. Disease Activity Only Moderately Correlates with Quality of Life Impairment in Patients with Chronic Spontaneous Urticaria. Dermatology. 2013;226:371-9.

18. Tavakol M, Mohammadinejad P, Baiardini I, Braido F, Gharagozlou M, Aghamohammadi A, et al. The persian version of the chronic urticaria quality of life questionnaire: factor analysis, validation, and initial clinical findings. Iran J Allergy Asthma Immunol. 2014;13:278-85

19. Dias GAC. Tradução e Validação para Língua Portuguesa do Questionário Específico para Avaliação da Qualidade de Vida em Pacientes com Urticária Crônica [dissertação]. Rio de Janeiro (RJ): Universidade Federal do Rio de Janeiro; 2011.

20. Zuberbier T, Greaves MW, Juhlin L, Kobza-Black A, Maurer D, Stingl G, et al. Definition, Classification, and Routine Diagnosis of Urticaria: A Consensus Report. J Investig Dermatol Symp Proc. 2001;6:123-7.

21. Baiardini I, Bousquet PJ, Brzoza Z, Canonica GW, Compalati E, Fiocchi A, et al. Recommendations for assessing Patient-Reported Outcomes and Health-Related quality of life in clinical trials on allergy: a GA2LEN taskforce position paper. Allergy. 2010;65:290-5

22. Lennox RD, Leahy MJ.Validation of the Dermatology Life Quality Index as an outcome measure for urticaria-related quality of life. Ann Allergy Asthma Immunol. 2004;93:142-6.
23. Sabroe RA, Seed PT, Francis DM, Barr RM, Black AK, Greaves MW. Chronic idiopathic urticaria: comparison of the clinical features of patients with and without anti-FcepsilonRI or anti-IgE autoantibodies. J Am Acad Dermatol. 1999;40:44350.

24. Zuberbier T, Balke M, Worm M, Edenharter G, Maurer M. Epidemiology of urticaria: a representative cross-sectional population survey. Clin Exp Dermatol. 2010;35:869-73

25. Maurer M, Weller K, Bindslev-Jensen C, Giménez-Arnau A, Bousquet PJ, Bousquet $\mathrm{J}$, et al. Unmet clinical needs in chronic spontaneous urticaria. A GA2LEN task force report. Allergy. 2011 Mar;66:317-30.

26. Ferrer M. Epidemiology, healthcare, resources, use and clinical features of different types of urticaria. Alergológica 2005. J Investig Allergol Clin Immunol. 2009;19:21-6.

27. Ibge.gov.br [Internet]. Censo dermográfico 2010. Trabalho e rendimento resultados da amostra. Rio de Janeiro: IBGE, 2012. [cited 2012 dez 22] Avaliable from: http://ibge.gov.br/Censos/Censo_Demografico_2010/ trabalho_ rendimento amostra.pdf.

28. Gaig P, Oloña M, Muñoz Lejarazu D, Caballero MT, Domínguez FJ, Echechipia S, García Abujeta JL, et al. Epidemiology of urticaria in Spain. J Investig Allergol Clin Immunol. 2004;14:214-20.

29. Yun J, Katelaris CH, Weerasinghe A, Adikari DB, Ratnayake C. Impact of chronic urticaria on the quality of life in Australian and Sri Lankan populations. Asia Pac Allergy. 2011;1:25-9.

30. Heng JK, Koh LJ, Toh MP, Aw DC. A study of treatment adherence and quality of life among adults with chronic urticaria in Singapore. Asia Pac Allergy. 2015:5:197-202.

31. Ue AP, Souza PK, Rotta 0, Furlani Wde J, Lima AR, Sabbag DS. Quality of life assessment in patients with chronic urticaria. An Bras Dermatol. 2011;86:897904.

32. Metz M, Giménez-Arnau A, Borzova E, Grattan CE, Magerl M, Maurer M. Frequency and clinical implications of skin autoreactivity to serum versus plasma in patients with chronic urticaria. J Allergy Clin Immunol. 2009;123:705-6.

33. Grigulis I B, Silveira HHN, Alves L, Cruz FCDF, Costa E, et al. Avaliação da qualidade de vida de pacientes com urticária crônica acompanhados em serviço de alergia e imunologia. Rev Bras Alergia Imunopatol. 2009;32:96-101.

34. Silvares MR, Fortes MR, Miot HA. Quality of life in chronic urticaria: a survey at a public university outpatient clinic, Botucatu (Brazil). Rev Assoc Med Bras. 2011;57:577-82

\author{
MAILING ADDRESS: \\ Gabriela Andrade Coelho Dias \\ Policlinica Piquet Carneiro - Setor de Alergia \\ Avenida Marechal Rondon 381 - São Francisco Xavier \\ 20950-003 - Rio de Janeiro - RJ \\ Brazil \\ E-mail: gabrielaacdias@gmail.com
}

How to cite this article: Dias GAC, Pires GV, Valle SOR, Dortas Junior SD, Levy S, França AT, Baiardini I, Canonica WG. Impact of chronic urticaria on the quality of life in universitary hospital's patients. An Bras Dermatol. 2016;91(6):754-9. 